\title{
Genotipicação de Clostridium perfringens isolados de frangos de corte através da PCR múltipla
}

\author{
Genotyping Clostridium perfringens broiler chickens isolates by multiplex PCR products analyses
}

\author{
Alexis de Matos Gomes ${ }^{I^{*}}$ Francisco Carlos Faria Lobato $^{\mathrm{I}}$ Nelson Rodrigo da Silva Martins ${ }^{\mathrm{I}}$ \\ Ronnie Antunes de Assis II
}

\section{RESUMO}

Clostridium perfringens ( $C p)$ é uma bactéria aneróbica gram positiva que, além de provocar gangrena gasosa e enterotoxemia em humanos e animais, constitui-se na principal causa de enterite necrótica em aves de criações intensificadas. A identificação dos isolados foi realizada pela reação de lecitinase em ágar TSC-gema de ovo, colônias com dupla hemólise em ágar sangue desfibrinado de eqüino, coloração de Gram e provas bioquímicas. Das amostras analisadas, $171 \mathrm{Cp}$ foram isolados em jejuno e íleo de frangos de corte provenientes de um frigorífico da região de Pará de Minas-MG. Cp foi isolado em 62 (49,6\%) de 125 amostras de conteúdo lumenal de jejunos e em 109 (87,2\%) de igual número de íleos dos frangos de corte. Utilizando-se a técnica da PCR múltipla para genotipicacão das estirpes de Cp, de acordo com os genes para as toxinas principais e letais (cpa, $c p b$, etx e iA), da toxina cpb2 (cpb2) e enterotoxina (cpe), as estirpes de Cp isoladas foram classificadas em cinco tipos toxigênicos (A-E). Das 62 estirpes de Cp isoladas do jejuno, foram obtidos $42 / 62(67,7 \%)$ tipo A, 1/62 (1,6\%) tipo A com produto de amplificação para o gene da toxina beta2, 0/62 (0\%) tipo B, 17/62 (27,4\%) tipo C, 1/62 (1,6\%) tipo D. Das 109 amostras de Cp isolados do íleo das aves foram obtidos $62 / 109$ (56,9\%) tipo A, 3/109 (2,7\%) tipo A com produto de amplificação para o gene da toxina beta2, 1/62 (0,9\%) tipo $B$, $38 / 109$ (34,9\%) tipo C, $1 / 109$ (0,9\%) tipo D. Cp A $(60,8 \%)$ Cp C $(32,2 \%)$ foram os tipos toxigênicos predominantes em conteúdo intestinal de frango de corte. Cinco $(2,9 \%)$ das 171 amostras de $\mathrm{Cp}$ isolados não foram tipificadas. Não foram detectados os genes codificadores das toxinas iota (iA) $e$ enterotoxina (сре) em nenhuma das 171 estirpes de Cp caracterizados.

Palavra-chave: enterite necrótica, tipos toxigênicos, frangos de corte, Clostridium perfringens.

\begin{abstract}
Clostridium perfringens (Cp) is an anaerobic grampositive bacterium which causes gaseous gangrene and enterotoxaemias in humans and domestic animals, besides being the primary cause of necrotic enteritis in poultry. $C P$ isolates were preliminary identified according to the lecithinase test on agar TSC-egg yolk, colony with double haemolysis in desfibrinated horse blood agar, Gram staining and biochemical tests. Cp isolates (171) were obtained from the intestinal content of broiler chickens sampled in a slaughterhouse in Pará de Minas city, MG, Brazil. Cp was isolated in 62/125 (49.6\%) strains from jejunum content and in 109/125 (87.2\%) of ileum. $C p$ strains were classified into five toxigenic types (A-E), using multiplex PCR assay for genotyping of the principal and lethal toxins in the detection of genes coding for toxins alfa, beta, epsilon e iota, nomely genes cpa, cpb, etx e iA genes, beta 2 toxin (cpb2) and enterotoxin (cpe). From a total of $62 \mathrm{Cp}$ jejunum isolates obtained 42/62 (67.7\%) were type A, 1/62 (1.6\%) type $A$ with the amplification of products for beta2 toxin gene $(A / B), 0 / 62(0 \%)$ type $B, 17 / 62(27.4 \%)$ type $C$ and 1/62 (1.6\%) type D. A total of 109 ileum Cp isolates were obtained being 62/109 (56.9\%) type A, 3/109 (2.7\%) type A/ $B$ toxin gene, 1/62 (0.9\%) type B, 38/109 (34.9\%) type C, 1/ 109 (0.9\%) type D. Cp A (60.8\%) and Cp C (32.2\%) toxigenic types were the most prevalent types in the analyzed intestinal contents of broiler chickens Cp A 104/171 (60.8\%) and 55/ $171(32.2 \%)$ toxigenic types which were the most prevalent types analyzed into two partes of the intestinal content of broiler chickens. Five (2.9\%) out of $171 \mathrm{Cp}$ isolates were not typified. The iota toxin (iA) and enterotoxin gene (сpe) codifying genes were not identified.
\end{abstract}

Key words: necrotic enteritis, toxinotyping, broiler chickens, Clostridium perfringens. IDepartamento de Medicina Veterinária Preventiva, Escola de Veterinária, Universidade Federal de Minas Gerais (UFMG), Belo
Horizonte, MG, Brasil. E-mail: alexisg@ig.com.br. *Autor para correspondência.

IILaboratório de Agropecuária do Ministério da Agricultura e Pecuária (MAPA), Pedro Leopoldo, MG, Brasil. 


\section{INTRODUÇÃO}

Cp é comumente encontrado na microbiota intestinal dos humanos e de animais sadios. Portanto, o aparecimento de patologias provocadas por esse microrganismo é dependente de circunstâncias que favoreçam o crescimento e a produção em doses elevadas das toxinas clostridiais.

A enterite necrótica (EN) por Cp em frangos de corte, que pode ocasionar grandes perdas econômicas, tem sido controlada, na criação comercial, com antimicrobianos promotores de crescimento nas rações das aves (MARTINS, 1987). A EN acomete frangos e poedeiras, de 2-4 semanas de idade, com taxa de mortalidade diária que pode exceder a $1 \%$ e curso clínico com duração de uma semana. A apresentação clínica da EN inclui depressão, falta de apetite, apatia, prostração, desidratação e morte. Entretanto, as perdas podem estar também relacionadas às manifestações subclínicas da doença, como diminuição da absorção de nutrientes, alta conversão alimentar e baixo ganho de peso.

Entre os fatores pré-disponentes importantes à EN, a infecção das aves por coccídeos favorecem a colonização e a multiplicação de Cp no trato intestinal. RIDDELL \& KONG (1992), ao estudarem a influência da dieta na EN, demonstraram que o tipo de alimento utilizado na composição da ração é um fator correlacionado à incidência da EN e ao índice de mortalidade em frangos de corte. De forma geral, as lesões de EN possuem maior freqüência em aves, cujas dietas são compostas de ingredientes de baixa digestibilidade e ricas polissacarídeos insolúveis.

Atualmente, a técnica de PCR múltipla vem sendo amplamente utilizada para genotipificação por meio da amplificação dos genes das toxinas principais - cpa (toxina alfa), cpb (toxina beta), etx (toxina épsilon) e iA (toxina iota) - e de outros genes de virulência - cpe (enterotoxina) e $c p b 2$ (toxina beta2).

O trabalho proposto tem como objetivos utilizar uma técnica de PCR múltipla como auxílio na identificação molecular de Cp em amostras de jejuno e íleo e determinar a prevalência dos tipos toxigênicos existentes na microbiota intestinal de frangos de corte.

\section{MATERIAL E MÉTODOS}

Como referência, foram obtidas estirpes de Cp dos tipos A, B, C, D e E do American Type Culture Collection (ATCC), dos Estados Unidos da América. Os liófilos foram reconstituídos pela adição de $1 \mathrm{~mL}$ de caldo tioglicolato. Após a reidratação das amostras de referência, uma alíquota de $200 \mu \mathrm{L}$ foi inoculada em um tubo de rosca contendo $15 \mathrm{~mL}$ de caldo tioglicolato e $100 \mu \mathrm{L}$ deste inóculo foi semeado por esgotamento em duas placas de ágar sangue suplementados com 10\% de sangue eqüino desfibrinado (ASA). O cultivo em caldo tioglicolato e uma das placas de ASA foram incubadas em atmosfera de anaerobiose a $37^{\circ} \mathrm{C}$ durante 48 horas $\left(\mathrm{CO}_{2}: 9,8 \% ; \mathrm{H}_{2}: 10,4 \% ; \mathrm{N}_{2}: 79,8 \%\right)$, sendo a outra placa de ASA destinada ao cultivo aeróbio à $37^{\circ} \mathrm{C}$ por 24 horas. Na seqüência, as amostras de referência foram avaliadas quanto às características morfotintoriais e à pureza pela coloração de Gram (SEBALD \& PETIT, 1997).

Foram coletadas 125 alças intestinais de frangos de corte, oriundas de um frigorífico da região de Pará de Minas-MG. Os animais permaneceram sete dias em restrição de antibióticos da ração de terminação, sendo sacrificados por eletronarcose e eviscerados, conforme a rotina de abate. Os intestinos foram atados com fio de algodão em ambas as extremidades e então o material foi acondicionado em temperatura de $4^{\circ} \mathrm{C}$, transportado até o local do experimento e processado em período máximo de duas horas. Das alças intestinais foi retirado $1 \mathrm{~g}$ de conteúdo lumenal de íleo e jejuno para inoculação em tubos de rosca contendo $20 \mathrm{~mL}$ de caldo tioglicolato. Os tubos foram incubados em atmosfera de anaerobiose a $37^{\circ} \mathrm{C}$ durante 48 horas. Logo após o crescimento do cultivo primário, foram realizados esfregaços corados pelo Gram repiques pela técnica de esgotamento em placas de ASA e ágar TSC suplementado com $5 \%$ de gema de ovo para demonstração da zona de dupla hemólise e reação de lecitinase, respectivamente (SEBALD \& PETIT, 1997).

As colônias características foram submetidas à classificação morfo-tintorial pelo Gram, cultivo aeróbio em ASA, e posteriormente foram repicadas em tubos contendo tioglicolato e nitritotripticase para a caracterização bioquímica pelas provas de fermentação de açúcares (glicose, salicina, sacarose, maltose e lactose), coagulação do leite-ferro, produção de indol, redução do nitrato, urease e hidrólise da gelatina (SEBALD \& PETIT, 1997).

O material genético de Cp das estirpes de referência e dos isolados de conteúdo lumenal foram obtidos a partir de colônias puras do cultivo em placas de ASA em jarra de anaerobiose, utilizando-se a extração sem purificação do DNA do método térmico. Após a adição de 23,2 $\mu \mathrm{L}$ de água Milli- $\mathrm{Q}^{\circledR}$ estéril, da “massa bacteriana” e do óleo mineral, os microtubos foram hermeticamente fechados e colocados em aparelho termociclador a $99^{\circ} \mathrm{C}$ por $1 \mathrm{~min}$. As amostras foram centrifugadas a $10.000 \mathrm{~g}$ por cinco minutos e o sobrenadante utilizado como molde de DNA (HEIKINHEIMO \& KORKEALA, 2005).

Ciência Rural, v.38, n.7, out, 2008. 
Para obtenção de um volume final de $50 \mu \mathrm{L}$ foram adicionados à PCR: água ultra pura (q. s. p.); DNA molde (10ng $\mu \mathrm{L}^{-1}$ ); Tampão 10X; $\mathrm{MgCl}$ (50mM); dNTP's (0,2mM); cpa senso (79,68nmoles); cpa reverso (81,04nmoles); $c p b$ senso (79,64nmoles); $c p b$ reverso (80,98nmoles); etx senso (84,04nmoles); etx reverso (81,12nmoles); iA senso (81,47nmoles); iA reverso (87,83nmoles); cpe senso (83,21nmoles); cpe reverso (73,21nmoles); cpb2 senso $(48,51)$; $c p b 2$ reverso (78,37nmoles); Taq DNA polimerase (2,5U). As condições de amplificação foram: $94^{\circ} \mathrm{C} 5 \mathrm{~min}^{-1}$ e 34 ciclos de $94^{\circ} \mathrm{C} 1 \mathrm{~min}^{-1} ; 48^{\circ} \mathrm{C} 1 \mathrm{~min}^{-1} ; 72^{\circ} \mathrm{C} 1 \mathrm{~min}^{-1}$ e uma extensão final de $72^{\circ} \mathrm{C} 7 \mathrm{~min}^{-1}$. Um volume de $12 \mu \mathrm{L}$ de cada produto obtido foi submetido à eletroforese por $30 \mathrm{~min}$ a $100 \mathrm{v}$, $300 \mathrm{~mA}$ em gel de agarose a $1,5 \%$ contendo $0,5 \mu \mathrm{g}$ de brometo de etídio $\mathrm{mL}^{-1}$. Marcador de peso molecular de 100 pares de base Molecular (Weight Marker 100pb DNA Ladter - Invitrogen - United States of America) foi utilizado como padrão de comparação. As bandas amplificadas foram visualizadas e fotodocumentadas sob luz ultravioleta .

Os iniciadores utilizados na reação foram sintetizados e testados em condições convencionais de PCR, bem como foi realizada a clonagem dos produtos amplificados que foram seqüenciados previamente (PERELLE et al., 1995). Durante a padronização e a validação do sistema de da PCR múltipla para $\mathrm{Cp}$, foram avaliados possíveis problemas relacionados à concentração de cada iniciador específico à montagem e funcionamento do sistema de amplificação múltipla, por meio de consultoria realizada pelo Laboratório de Genética de Microrganismos do Instituto de Ciências Biológicas da Universidade Federal de Minas Gerais.

\section{RESULTADOS E DISCUSSÃO}

Das 250 amostras de conteúdo lumenal de íleo e jejuno analisadas, 171 (68,4\%) demonstraram características morfo-tintoriais e bioquímicas compatíveis com $\mathrm{Cp}$, apresentando bastonetes gram positivos curtos, colônias arredondadas, umbilicadas, brilhantes com zona de dupla hemólise no ASA e ausência de crescimento em anaerobiose. As provas bioquímicas destes isolados foram positivas para glicose, salicina, sacarose, maltose, lactose, gelatina, nitrito e leite-ferro; sendo negativas para indol e urease, apresentando características bioquímicas de $\mathrm{Cp}$, de acordo com a chave de classificação do gênero Clostridium (SEBALD \& PETIT, 1997). A reação de lecitinase em ágar TSC com gema de ovo demonstrou ser um método adequado e prático para identificação fenotípica das estirpes isoladas de $\mathrm{Cp}$, revelando a presença da toxina alfa pela hidrólise da lecitina. As colônias lecitinase positivas foram identificadas por meio do halo brancacento em volta das colônias cremosas.

Acredita-se que o achado da amostragem estudada de 68,4\% de Cp isolados demonstra que a adição de antibióticos controla os índices de mortalidade por de EN nos plantéis de frangos de corte SCHOCKEN-ITURRINO et al. (1999), ao avaliarem a composição da microbiota intestinal de frangos de corte submetidos às dietas suplementadas com antibióticos, apresentando baixo ganho de peso e escore leve de diarréia, obtiveram percentual de isolamento de Cp de 16,78\% em 94 de 374 amostras do gênero Clostridium. Apesar de os antibióticos serem de ampla utilização na avicultura intensiva de corte do Brasil, há uma pressão para sua retirada das dietas dos frangos, com base nos estudos dos efeitos deletérios dos resíduos na carne para a saúde humana, principalmente devido à seleção de linhagens de bactérias resistentes aos antimicrobianos, podendo haver transferência horizontal dos genes responsáveis pela resistência da bactérias nos mais diversos ecossistemas, principalmente no trato gastrointestinal de humanos e animais. O uso contínuo de antibióticos pode representar embargo comercial para a exportação de carne de frango, além de tornar-se sério problema de saúde pública mundial (COUCIL OF THE EUROPEN UNION, 2003).

Na semana que antecede o abate, os antibióticos são retirados das formulações das rações dos frangos de corte, em observância ao período de carência pela utilização destes antimicrobianos promotores de crescimento, o que representa em diminuição dos custos para o produtor. Durante o experimento, o efeito da retirada do antibiótico demostrou facilitar o isolamento de Cp em 49,6\% dos conteúdos intestinais de íleos e de 87,2\% dos jejunos. Desse modo, em ocasião da retirada dos promotores de crescimento, os frangos de corte estariam predispostos a alguma forma de infecção entérica por Clostridium perfringens, principalmente a EN sublclínica, conforme já vem sendo relatado em vários países.

Por meio da tipificação toxigênica pela PCR múltipla foi demonstrado que dos 171 isolados de $\mathrm{Cp}$, 104 (60,82\%) foram do tipo A, 4 (2,34\%) do tipo A com amplificação para o gene da toxina beta2, $1(0,58 \%)$ tipo B, 55(32,16\%) tipo C, 2 (1,18\%) tipo D. Cinco (2,92\%) das 171 amostras não foram tipificadas, bem como não houve amplificação para o gene codificador das toxinas iota (iA) e enterotoxina (cpe). A figura 1 apresenta os resultados da amplificação dos fragmentos dos genes cpa (324pb), cpb (196pb), etx (655pb) e iA (233pb) das estirpes de $\boldsymbol{C}$. perfringens ATCC (A-E) utilizadas como controles positivos da PCR múltipla. 


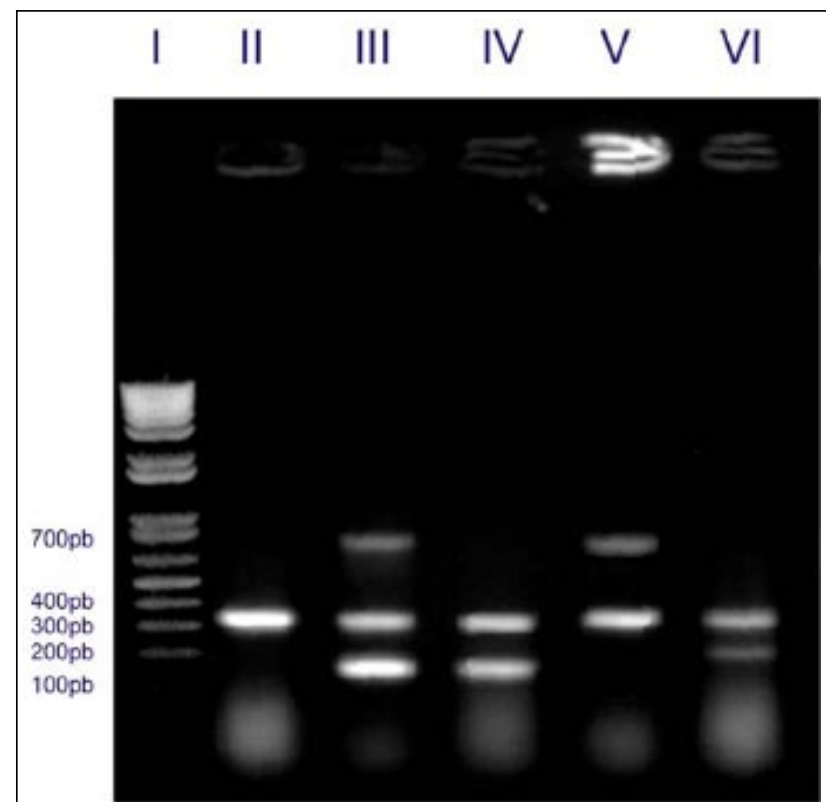

Figura 1 - Fotodocumentação de gel de agarose da PCR múltipla de material genético extraído de Clostridium perfringens AE. Canaleta I. marcador de peso molecular $(1 \mathrm{~kb})$ Canaleta II. Cp A amostra positiva para cpa (324pb) Canaleta III. Cp B amostra positiva para cpa (324pb), cpb (196pb) e etx (655p) Canaleta IV. Cp C amostra positiva para cpa (324pb) e $c p b$ (196pb) Canaleta V. Cp D amostras positiva para cpa (324pb) e etx $(655 \mathrm{pb})$ Canaleta VI. Cp E amostra positiva para $c p a(324 \mathrm{pb})$ e iA (233pb).

A tipificação toxigênica de Cp nesta amostragem de jejuno e íleo de frangos de corte demostrou que os Cp A e Cp C são prevalentes no conteúdo intestinal em frangos de corte hígidos, em concordância com recente estudo realizado na Turquia, por KALENDER \& ERTAS (2005), que apontaram estes tipos toxigênicos de Cp como principais agentes etiológicos de EN em frangos de corte. Segundo o mesmo estudo, o Cp D está associado aos surtos de EN neste país em menor prevalência.

$\mathrm{Na}$ atualidade, tem se discutido, além da minimização dos prejuízos com a EN clínica e subclínica em frangos de corte, a adequação às novas exigências do mercado internacional, que preconizou a retirada dos antimicrobianos promotores de crescimento na União Européia a partir de 2006 (COUCIL OF THE EUROPEN UNION, 2003). Além disso, não estão determinados os efeitos quantitativos dos diversos antimicrobianos promotores do crescimento utilizados na avicultura industrial sobre a dinâmica populacional do trato gastrointestinal das aves, em especial, no controle da microbiota anaeróbica gram positiva no microambiente intestinal (PEDROSO, 2003). Em nosso estudo, a utilização de antibióticos nas rações de frangos de corte não produziu modificações quantitativas notáveis na microbiota intestinal, no que diz respeito aos tipos toxigênico, em especial aos Cp A e Cp C, que são os tipos mais comumente encontrados na etiologia da EN dos frangos. Cp A e Cp C tem sido relatado como o tipo toxigênico dominante na microbiota intestinal de frangos de corte, corroborando os resultados encontrados em nosso estudo, e também os resultados encontrados por ENGSTRÖM et al. (2003). O mesmo autor atenta para o potencial impacto para a saúde pública, advindo da ingestão de carne de frangos contaminados com $\mathrm{Cp}$ A do conteúdo intestinal do frango, durante o procedimento de abate. CRAVEN et al. (2001) isolaram Cp A em 13 carcaças de frangos e obtiveram percentual de 81\% de isolamento de Cp A em único plantel de 16 aves, evidenciando a importância do achado em amostras de conteúdo intestinal. A diferença no percentual de isolamento entre jejuno e íleo pode ser associada aos diferentes efeitos das concentrações inibitórias dos antibióticos sobre a microbiota intestinal nos diferentes sítios do trato gastrointestinal. Os antimicrobianos podem atuar na pressão de seleção sobre a microbiota gram positiva em algumas das secções do lúmen intestinal, podendo influenciar nos mecanismos de adesão e colonização de Cp, na parede do intestino delgado (EDENS, 2003).

Por se desconhecer a ação da pressão destes antibióticos sobre a diminuição do grau de patogenicidade ou de agressão das estirpes de Cp (MARTINS, 1987), torna-se importante avaliar por meio do estudo epidemiológico da tipificação toxigênica Cp em amostragem de conteúdo lumenal de jejuno e íleo, associando às manifestações clínicas e ao escore das lesões intestinais, a incidência da formas subclínicas da EN e os reflexos das perdas econômicos por EN nos plantéis de frangos de corte. Com a utilização de antibióticos nas rações de frango de corte, a população de Cp parece não ser controlada de forma qualitativa, quanto ao tipos toxigênicos A e C. Porém, as diferenças de percentual de isolamento entre jejuno e íleo, em termos quantitativos, pode ser devido ao reflexo da restrição de antibióticos na ecologia do TGI, atuando no aumento da carga de Cp no lúmen intestinal e influenciando os mecanismos de adesão dos mesmos nos enterócitos (MACARI \& FURLAM, 2005).

\section{CONCLUSÕES}

Cp dos tipos toxigênicos A e C são predominantes na amostragem de conteúdo lumenal 
de jejuno e íleo de frangos de corte. Não foram encontrados isolados de Cp E e não houve amplificação do gene cpe . Quanto à escolha do sítio para o isolamento, o íleo foi superior ao jejuno e houve variação quantitativa entre as amostras. Quanto à composição da microbiota intestinal, os tipos toxigênicos de $\mathrm{Cp}$ foram semelhantes para as amostras jejuno e íleo e não houve variação qualitativa entre elas. Nas condições em que foi realizado o experimento, o sistema de PCR múltipla para genotipagem de Cp tipo A, B, C, D e E mostrou-se satisfatório.

\section{REFERÊNCIAS}

COUCIL OF THE EUROPE UNION. Council regulation on the authorisation of the additive avilamycin in feedingstuffs. 2003. Capturado em 05 set. 2007. Online. Disponível em: http:// register. Consilium. eu. int/ pdf/en/03/ st06/st06120en03.pdf.

CRAVEN, S. E. et al. Incidence of Clostridium perfringens in broiler chickens and their environment during production and processing. Avian Diseases, v.45, n.4, p.887-896, 2001.

EDENS, F.W. An altenative for antibiotic use in poultry: probiotics. Revista Brasileira de Ciência Avícola, v.5, p.1-40, 2003.

ENGSTRÖM, B.E. et al. A molecular typing of isolates of Clostridium perfringens from healthy and diseased poultry. Veterinary microbiology, v.94, n.3, p.225-235, 2003.

HEIKINHEIMO, A.; KORKEALA, H. Multiplex PCR assay for toxinotyping isolates obtained from finnish broiler chickens. Letter in Applied Microbiology, v.40, p.407-411, 2005.
KALENDER, H.; ERTAS, H.B. Isolation de Clostridium perfringens from chickens and detection of the alpha toxin gene by polymerase chain reaction (PCR). Turkey Journal Veterinary Animal Science, v.29, p.847-850, 2005.

MACARI, M.; FURLAM, R.L. Probióticos. In: CONFERÊNCIA APINCO 2005 DE CIENCIA E TECNOLOGIA AVÍCOLA, 2005, Campinas, SP. Anais... Campinas: FACTA, 2005. V.1, $24 p$.

MARTINS, P.C. Infecções clostridiais em avicultura. São Paulo: APINCO, 1987. 3p. (Boletim Técnico).

PEDROSO, A.A. Estrutura da comunidade de Bacteria do trato intestinal de frangos suplementados com promotores de crescimento. 2003. 103f. Tese (Doutorado em Agronomia) - Curso de Pós-graduação em Ciência Animal e Pastagens, Escola Superior de Agricultura "Luiz de Queiroz” da Universidade do Estado de São Paulo.

PERELLE, S. et al. Characterization of Clostridium perfringens iota-toxin genes and expression in Escherichia coli. Infection and Immunology, v.63, n.12, p.5147-5156, 1995.

RIDDELL, C.; KONG, X. The influence of diet on necrotic enteritis in broiler chicken. Avian Diseases, v.36, p.499-503, 1992.

SEBALD, M.; PETIT, J.C. Identification des Clostridium species. In: Méthodes de laboratoire bactéries anaérobies et leur identification. 2.ed. Paris: Institut Pasteur, 1997. p.262-263.

SCHOCKEN-ITURRINO, R.P. et al . REUNIÃO ANUAL DA SOCIEDADE BRASILEIRA DE ZOOTECNIA, 26., 1999, Porto Alegre, RS. Anais... Porto Alegre: Sociedade Brasileira de Zootecnia, 1999. p.149-151. 